\title{
Inhibition of glycogen synthase kinase-3 alleviates Tcf3 repression of the pluripotency network and increases embryonic stem cell resistance to differentiation
}

\author{
Jason Wray ${ }^{1,4}$, Tüzer Kalkan ${ }^{1}$, Sandra Gomez-Lopez ${ }^{1,5}$, Dominik Eckardt ${ }^{2,6}$, Andrew Cook ${ }^{3}$, \\ Rolf Kemler ${ }^{2}$, and Austin Smith ${ }^{1}$ \\ ${ }^{1}$ Wellcome Trust Centre for Stem Cell Research \& Department of Biochemistry, University of \\ Cambridge, Tennis Court Road, Cambridge, United Kingdom, CB2 1QR \\ ${ }^{2}$ Max-Planck Institute of Immunobiology, Stubeweg 51, D-79108 Freiburg, Germany \\ ${ }^{3}$ World Wide Medicinal Chemistry, Pfizer Ltd, Sandwich, Kent, CT13 9NJ, United Kingdom
}

\section{Abstract}

Self-renewal of rodent embryonic stem (ES) cells is enhanced by partial inhibition of glycogen synthase kinase- $3(\mathrm{Gsk} 3)^{1}{ }^{1}$. This effect has variously been attributed to stimulation of $\mathrm{Wnt}$ signalling via $\beta$-catenin ${ }^{1}$, stabilisation of $\mathrm{cMyc}^{3}$, and global de-inhibition of anabolic processes ${ }^{4}$. Here we demonstrate that $\beta$-catenin is not necessary for ES cell identity or expansion, but its absence eliminates the self-renewal response to Gsk3 inhibition. Responsiveness is fully restored by truncated $\beta$-catenin lacking the $\mathrm{C}$-terminal transactivation domain ${ }^{5}$. However, requirement for Gsk3 inhibition is dictated by expression of Tcf3 and mediated by direct interaction with $\beta$ catenin. Tcf3 localises to many pluripotency genes ${ }^{6}$ in ES cells. Our findings confirm that Tcf3 acts as a transcriptional repressor and reveal that $\beta$-catenin directly abrogates Tcf 3 function. We conclude that Gsk3 inhibition stabilises the ES cell state primarily by reducing repressive influence on the core pluripotency network.

\begin{abstract}
Canonical Wnt signalling is a key regulator of stem cells in epithelial tissues (reviewed in ${ }^{7}$ ). This pathway has also been proposed to play a major role in self-renewal of pluripotent embryonic stem (ES) cells. Wnt ligands promote nuclear accumulation of $\beta$-catenin, which associates with DNA-bound Tcf/Lef factors and activates transcription ${ }^{8}{ }_{-10}$. Glycogen synthase kinase- 3 (Gsk 3$)^{1},{ }^{11}$ negatively regulates Wnt signalling by phosphorylating $\beta$ catenin leading to its ubiquitination and proteolysis ${ }^{12},{ }^{13}$. This is prevented by inhibitors of Gsk3 which thereby act as mimetics of Wnt stimulation. Gsk3 inhibitors such as BIO or CHIRON99021 (CH) support short term expansion of mouse ES cells ${ }^{1},{ }^{2}$ and this has been interpreted as evidence for canonical Wnt function in self-renewal ${ }^{1},{ }^{6},{ }^{14}$. Differentiation is only partially suppressed, however, and cultures collapse upon passaging ${ }^{2}$. Robust and longterm self-renewal additionally requires the cytokine leukaemia inhibitory factor (LIF), which activates the transcription factor Stat $3^{15},{ }^{16}$, or inhibition of the mitogen activated protein kinase (Mapk) cascade ${ }^{17}$.
\end{abstract}

\footnotetext{
${ }_{5}^{4}$ Current address: Cancer Institute, University College London, Paul O'Gorman Building, 72 Huntley Street, London, WC1E 6BT ${ }^{5}$ Current address: Instituto de Fisiología Celular, División de Neurociencias, UNAM. Circuito Exterior s/n, Ciudad Universitaria, México D. F. 04510

${ }^{6}$ Current address: Miltenyi Biotec GmbH, Friedrich-Ebert-Straße 68, 51429 Bergisch Gladbach, Germany

Author Contributions JW performed, analysed and interpreted experiments, TK created and validated the Rex $1 \mathrm{GFPd} 2$ reporter, SGL generated CreIres-fluorescent protein plasmids, DE and RK generated floxed $\beta$-catenin ES cells, AC selected and provided Gsk3 inhibitors, AS supervised the study and wrote the paper together with JW.
} 
Deletion of $T c f 3$ can delay ES cell differentiation ${ }^{18},{ }^{19}$ but, unlike other Tcfs, evidence that $\beta$-catenin directly activates Tcf3 target genes is lacking. Significantly, genetic analyses in the embryo ${ }^{20},{ }^{21}$ have not revealed a requirement for Wnt in the naive epiblast, the counterpart of ES cells. Furthermore, Gsk3 is a negative regulator of proteins involved in metabolism, transcription, translation, cell cycle, anti-apoptosis and signal transduction ${ }^{4}$. Its inhibition therefore has potentially much broader effects than canonical Wnt signalling. Importantly, Gsk3 inhibition is not necessary for ES cell propagation if LIF and inhibition of the Mapk cascade are combined ${ }^{2}$ or if LIF is used with serum or Bmp4 ${ }^{22}$.

Selectivity is a general concern with the use of kinase inhibitors. $\mathrm{CH}$ has limited crossreactivity with many other kinase ${ }^{23}$, but similar information is not available for BIO. We tested 7 proprietary Gsk3 inhibitors (Supplementary Information, Fig. S1). These compounds have distinct chemical structures, reducing the likelihood of shared off-target effects. In combination with the Mek inhibitor PD0325901 (PD), all promoted undifferentiated ES cell expansion over several passages in bulk culture and enabled colony formation at clonal density in a dose-dependent manner (Fig. 1a). Some of these compounds are effective at nanomolar concentrations. Interestingly, at slightly higher concentrations colony formation was reduced (see compounds C-G, Fig. 1a). We have also observed this effect for $\mathrm{CH}$ (data not shown) and infer that incomplete inhibition of Gsk3 is optimal. To test further whether Gsk3 is the critical target we carried out a genetic perturbation. We previously showed that ES cells lacking both isoforms of $\mathrm{Gsk} 3^{24}$ can be maintained using a Mek inhibitor alone without $\mathrm{CH}^{2}$. However, adaptation of these cells during repeated gene targeting manipulations cannot be excluded. We therefore transfected ES cells with siRNAs against $G s k 3 a, G s k 3 \beta$ or both, and scored formation of undifferentiated ES cell colonies at low density in the presence of PD. Immunoblotting confirmed specific knockdown of Gsk $3 \alpha$ and $\beta$ (Supplementary Information, Fig. S2). In wild-type ES cells double knock down produced a small increase in colony number while single knock downs had no effect (data not shown). We then tested ES cells in which one Gsk3a and both $G s k 3 \beta$ alleles have been inactivated ${ }^{24}$. Gsk3a siRNAs reproducibly increased undifferentiated colony formation by approximately three-fold in these cells while $G s k 3 \beta$ siRNAs had no effect, testifying to the specificity of the siRNA-response (Fig. 1b). Collectively these results validate the conclusion that reduced activity of Gsk3 enhances ES cell self-renewal.

To investigate the involvement of $\beta$-catenin we used ES cells carrying null and floxed alleles $\left(\beta c a t^{f l-}\right)$. Following transient transfection with CreIresGFP, cells were sorted by flow cytometry and plated in N2B27 with PD and CH (2i) plus LIF (2i+LIF, Supplementary Information, Fig. S3a). The GFP negative (non-transfected) population produced compact colonies typical of ES cells in 2i, while the GFP fraction yielded colonies of dispersed cells (Fig. 1c). Both expanded after picking and clonal lines were maintained thereafter in 2i+LIF. Immunoblotting confirmed that the dispersed cells had undergone deletion (Supplementary Information, Fig. S3b). Interestingly, these $\beta$-catenin-null $\left(\beta c a t^{\Delta /-}\right)$ ES cells re-established cell-cell contacts and normal ES cell colony morphology within 3 passages, even though $\beta$ catenin protein remained undetectable (Supplementary Information, Fig. S3b and Fig. 1d). As reported in the accompanying manuscript by Lyashenko et al., this adaptation is most likely due to compensatory up-regulation of plakoglobin ${ }^{21}$ which can replace $\beta$-catenin in adherens junctions.

$\beta c a t^{\Delta /-}$ cells expressed Nanog and Oct4 (Fig. 1d,e; Supplementary Information Fig. S3b) and readily formed alkaline phosphatase-positive colonies at clonal density (Fig. 2a). By immunostaining, Nanog appears at a similar level in all cells, suggesting that $\beta c a t^{\Delta /-}$ ES cells in $2 \mathrm{i}+\mathrm{LIF}$ are uniformly undifferentiated (Fig. 1d). We compared marker gene expression in $2 \mathrm{i}+\mathrm{LIF}$ to post-implantation epiblast stem cell (EpiSC)s ${ }^{25}{ }^{27}$ (Supplementary Information, Fig. S3c) and to cultures in activin and FGF2 which induces ES cell 
differentiation into EpiSCs (Fig. 1e). Null cells in 2i + LIF expressed ground state ES cell markers Klf4, Klf2 and $\mathrm{NrOb} 1$ and lacked the early differentiation marker Fgf5, whereas after culture in activin and FGF2 they showed the reciprocal pattern characteristic of EpiSCs. Previous reports of a partly differentiated phenotype of $\beta$-catenin-null cells ${ }^{28},{ }^{29}$ may therefore reflect characterisation of EpiSCs rather than ES cells. Interestingly the null cells failed to up-regulate brachyury in EpiSC culture, consistent with this being a canonical Wnt $\operatorname{target}^{30}$.

Wild type ES cells can be cultured from single cells in $2 \mathrm{i}+$ LIF or with slightly lower efficiency using any two of these components ${ }^{31} \cdot \beta c a t^{\Delta /-}$ cells in contrast formed no colonies in $2 \mathrm{i}$ and very few in CH+LIF. Only when both PD and LIF were present was colony formation robust (Supplementary Information, Fig. S3d and Fig. 2a). Stable transfection with a $\beta$-catenin transgene (Supplementary Information, Fig. S3e) restored clonal expansion in $2 \mathrm{i}$ or $\mathrm{CH}+\mathrm{LIF}$ (Fig. 2a). These results establish that the effect of Gsk3 inhibition is in large part mediated via $\beta$-catenin. Nonetheless, colony yield from $\beta c a t^{\Delta /-}$ cells was rather higher in 2i+LIF than in PD+LIF. This result was consistent with three alternative Gsk3 inhibitors (Supplementary Information, Fig. S4). Therefore $\beta$-catenin-independent effects of Gsk3-inhibition contribute to maximise ES cell clonogenicity.

We inserted destabilised GFP (GFPd2 ${ }^{32}$ ) into the Rex 1 locus of $\beta$ cat ${ }^{f l-}$ ES cells and then generated $\beta c a t^{\Delta /-}$ derivative clones, $\mathrm{CreC}$ and $\mathrm{CreD}$ (Supplementary Information, Fig. S5a,b). Rex 1 is down-regulated at the onset of ES cell differentiation ${ }^{33}$. In $2 \mathrm{i}+\mathrm{LIF}$ or PD $+\mathrm{LIF}$, both the $\beta c a t^{f l /-}$ and $\beta c a t^{\Delta /-}$ ES cells were almost uniformly GFP-positive (Fig. 2b), as reported for other markers in these defined conditions ${ }^{31}$. In $2 \mathrm{i}$ or CH+LIF, however, while $\beta c a t^{f l /}$ cells retained GFP, CreC and CreD cells lost expression. The pluripotencyassociated cell surface marker, PECAM ${ }^{34}$, behaved in the same manner (Supplementary Information, Fig. S6a). We then assayed colony formation after a $48 \mathrm{~h}$ period in the different conditions. $\beta c a t^{f l /}$ cells produced undifferentiated colonies in all cases except after culture in N2B27 alone (Fig. $2 \mathrm{c}$ ). $\beta c a t^{\Delta /-}$ cells produced colonies after $48 \mathrm{~h}$ in $2 \mathrm{i}+\mathrm{LIF}$ or PD+LIF but not following culture in $2 \mathrm{i}$ or $\mathrm{CH}+\mathrm{LIF}$.

We cultured Rex 1 GFPd 2 cells for 48 hours in CH, PD or LIF alone. PD or LIF delayed down-regulation of Rex $1 \mathrm{GFP}$ in $\beta c a t^{f l /-}$ and $\beta c a t^{\Delta /-}$ cells (Supplementary Information, Fig. S5c) whereas CH maintained GFP in floxed but not in null cells (Fig. 2d). Similar results were obtained in the presence of serum (Supplementary Information, Fig. S5d). In line with Rex 1GFP, down-regulation of Nanog was delayed by PD or LIF but not by $\mathrm{CH}$ in $\beta c a t^{\Delta /-}$ cells (Supplementary Information, Fig. S6b). qRT-PCR analysis confirmed that $\mathrm{CH}$ maintained expression of naïve pluripotency markers and suppressed up-regulation of early differentiation markers in $\beta c a t^{f l /-}$ ES cells (Fig. 2e). In contrast, $\beta c a t^{\Delta /-}$ ES cells, lost naive markers and up-regulated ectodermal markers Fgf5 and Sox3. Activated caspase-3 was not increased (Supplementary Information, Fig. S6c) indicating that apoptosis is not induced. These results indicate that Gsk3 inhibition resists exit from naïve pluripotency and that this response is dependent on $\beta$-catenin.

$\beta$-catenin interacts with Tcf/Lef transcription factors and can activate their targets via its $\mathrm{C}$ terminal transcriptional activation domain ${ }^{10}$. To test the requirement for $\beta$-catenin-mediated transcriptional activation we established clonal $\beta c a t t^{\Delta /-}$ "rescue" lines stably expressing fulllength $\beta$-catenin (RescueWT) or truncated $\beta$-catenin $\Delta \mathrm{C}$ (Rescue $\Delta \mathrm{C})$, which lacks the $\mathrm{C}$ terminal transactivation domain ${ }^{5}$ (Fig. 3a). Both full-length and $\beta$-catenin $\Delta C$ localised primarily to the cell membrane (Supplementary Information, Fig. S7). RescueWT but not Rescue $\Delta \mathrm{C}$ transfectants activated TOPFlash in response to $\mathrm{CH}$ (Fig. 3b). We tested differentiation sensitivity by culture for $48 \mathrm{~h}$ with $\mathrm{CH}$ only followed by replating. Both RescueWT and Rescue $\Delta \mathrm{C}$ cells produced undifferentiated colonies indicating restored 
response to $\mathrm{CH}$ (Fig. 3c). Down-regulation of the pluripotency markers Nanog and Klf4 and up-regulation of the early differentiation marker $\mathrm{Fgf5}$ were similarly suppressed by $\mathrm{CH}$ in RescueWT and Rescue $\Delta$ C cells (Fig. 3d). These data demonstrate that the canonical transcriptional activation mechanism is not required for $\beta$-catenin to increase ES cell resistance to differentiation.

$\beta$-catenin $\Delta \mathrm{C}$ cannot function as a transcriptional activator, but it retains domains for interaction with Tcf/Lef factors. Tcf3 is the predominant Tcf/Lef in ES cells and has been reported to behave primarily as a repressor ${ }^{18}$. $\beta$-catenin might relieve Tcf3-mediated repression ${ }^{18}$. This can explain why $A x i n 2$ and $C d x 1$, which are induced by $\mathrm{CH}$ in RescueWT cells are also more modestly induced in Rescue $\Delta \mathrm{C}$ cells (Fig. 3e). Intriguingly $T c f 3$ deletion results in delayed ES cell differentiation ${ }^{18},{ }^{19}$. We deployed siRNA in $\operatorname{Rex} 1 \mathrm{GFPd} 2$ reporter cells to investigate whether the $T c f 3$ loss-of-function phenotype ${ }^{18}$ is dependent on $\beta$-catenin. Rex 1 GFP down-regulation following withdrawal from $2 \mathrm{i}+\mathrm{LIF}$ was reduced by Tcf3 siRNA in both $\beta c a t^{f l /-}$ and $\beta c a t^{\Delta /-}$ ES cells (Fig. 4a). Tcf3 knock down (Supplementary Information, Fig. S8a) also maintained Nanog and Klf4 expression in both $\beta c a t^{f l-}$ and $\beta c a t^{\Delta /-}$ ES cells (Fig. 4b). Expression of canonical Wnt pathway targets Axin2 and $C d \times 1$ was increased by $T c f 3$ siRNA, independent of $\beta$-catenin (Fig. $4 \mathrm{~b}$ ), confirming that increased transcription of some Tcf targets does not require direct activation by $\beta$-catenin.

Tcf3-null ES cells ${ }^{18}$ self-renew robustly in LIF or PD alone and are insensitive to $\mathrm{CH}$ (Fig. $4 c, d)$, suggesting that a requirement for Gsk3 inhibition is dictated by Tcf3. To test whether the effect of $\mathrm{CH}$ involves direct interaction of $\beta$-catenin with Tcf3 we established Tcf3-null ES cell lines expressing wild-type Tcf3 (Tcf3WT) or Tcf3 lacking the $\beta$-catenin binding domain $(\mathrm{Tcf} 3 \Delta \mathrm{N})$ (Supplementary Information, Fig. S8b). Both Tcf3WT and Tcf3 $\Delta \mathrm{N}$ suppress activation of the TOPFlash reporter by $\mathrm{CH}$ (Fig. 5a). Similarly, both reduced expression of $C d x 1$ (Fig. 5b). Consistent with insensitivity to $\beta$-catenin, $\operatorname{Tcf} 3 \Delta \mathrm{N}$ was the more effective repressor of this endogenous Wnt target. In PD alone Tcf3-null ES cells efficiently formed undifferentiated colonies whereas both Tcf3WT and Tcf $3 \Delta \mathrm{N}$ transfectants behaved like wild type and failed to clone (Fig. 5c). Addition of $\mathrm{CH}$ restored colony forming efficiency by Tcf $3 W T$ cells. In contrast cells expressing Tcf $3 \Delta \mathrm{N}$ formed very few colonies. Importantly, however, they produced undifferentiated colonies at similar frequency to other cells in PD+LIF. Interestingly, the addition of $\mathrm{CH}$ in this condition increased colony numbers for both $\mathrm{Tcf} 3 \mathrm{WT}$ and $\mathrm{Tcf} 3 \Delta \mathrm{N}$ cells. These data demonstrate that the response to $\mathrm{CH}$ is largely mediated by a direct interaction between Tcf3 and $\beta$-catenin but also confirm that additional effects downstream of Gsk3 inhibition promote maximal ES cell self-renewal.

Tcf3 binds in proximity to many gene promoters that are also bound by Oct 4 and has been proposed as a component of a recursive circuit at the core of the pluripotent transcriptome ${ }^{6}$, $35,{ }^{36}$. By chromatin immunoprecipitation (ChIP) we confirmed detection of Tcf3 at promoters of KIf2 and Nodal (Fig. 5d) ${ }^{36}$. In the presence of PD and LIF we found that these and other candidate Tcf 3 targets showed no consistent transcriptional up-regulation on addition of $\mathrm{CH}$ (data not shown). However, $\mathrm{CH}$ has minimal functional impact in this context (Fig. 2a,b,c). Cells cultured for 24 hours without $2 \mathrm{i}+\mathrm{LIF}$ alone down-regulate naive genes preparatory to commitment. In these conditions addition of $\mathrm{CH}$ reproducibly induced up-regulation of Klf 2 and Nodal (Fig. 5e). This effect was $\beta$-catenin-dependent but was observed in Rescue $\Delta \mathrm{C}$ cells indicating that it is not mediated by canonical activation. We also found that Tcf 3 target genes $6,{ }^{36}$ were up-regulated when $\mathrm{CH}$ was added to ES cells in LIF and serum (Supplementary Information, Fig. S8c).

Canonical Wnt signalling has been proposed to support pluripotency by converting Tcf3 complexes from repressors to activators or by displacing Tcf3 with other Tcfs through which 
$\beta$-catenin activates transcription ${ }^{6}$. However, a simpler model is indicated by the findings that: (i) loss of Tcf3 phenocopies inhibition of Gsk3 even in the absence of $\beta$-catenin; (ii) transcriptionally inactive $\beta$-catenin fully restores responsiveness to Gsk3 inhibition; and, (iii) full responsiveness to $\mathrm{CH}$ requires interaction between $\beta$-catenin and $\mathrm{Tcf} 3$. We propose that $\beta$-catenin abrogates Tcf3 repression and that this is sufficient to permit transcription at Tcf3 target genes that are also bound by pluripotency factors (Fig. $5 \mathrm{f}, \mathrm{g}$ ).

Recently Kelly et al ${ }^{37}$ proposed a model in which $\beta$-catenin acts to inhibit differentiation of ES cells independent of activation of Tcf/Lef targets. Interaction with Oct 4 and modulation of Oct 4 target genes is proposed to account for the effects of $\beta$-catenin stabilisation downstream of Gsk 3 inhibition. However, these authors did not consider Tcf3. The data they present are consistent with our findings and can be explained by $\beta$-catenin-mediated derepression of Tcf3 targets, including Oct $4^{36}$. Furthermore, the reported interaction between $\beta$-catenin and Oct $4{ }^{37}$ could reflect recruitment of $\beta$-catenin by Tcf3 to promoter sites co-occupied by Oct 4 .

In the mouse embryo, genetic analyses have not revealed a function for canonical Wnt signalling in early epiblast cells ${ }^{21}$, although a later role in axis formation in vertebrate embryos is well-defined ${ }^{20},{ }^{21},{ }^{38}$. Wnt signalling has been shown to promote differentiation in ES cell-derived embryoid bodies ${ }^{39}$ and characterised targets induced by the canonical pathway in differentiating ES cells include mesodermal lineage specification genes such as brachyury ${ }^{30}$. Exit from naïve pluripotency and entry into differentiation may be associated with up-regulation of other Tcfs and a switch in the mode of action of $\beta$-catenin from derepression of Tcf3 to direct transcriptional activation. It should also be noted that the cell adhesion role of $\beta$-catenin is crucial for differentiation, as documented in the accompanying paper from Lyashenko et al.

Characterisation of $\beta$-catenin-null ES cells establishes that $\beta$-catenin is not essential for maintenance of the pluripotent ground state. However, $\beta$-catenin does mediate the additional resistance to differentiation conferred by inhibition of Gsk3. This facultative recruitment of $\beta$-catenin is only required if ES cells are cultured without LIF. Consistent with this, Stat3null ES cells are dependent on inhibition of Gsk32. It is important to note, however, that although the two pathways can substitute for one another they also have independent effects because ES cells cannot be stably maintained by LIF or $\mathrm{CH}$ alone but thrive in the presence of both ${ }^{31}$. Furthermore, addition of LIF to $2 \mathrm{i}$ or of $\mathrm{CH}$ to PD+LIF increases clonogenicity and for some mouse strains and the rat the combination of all three is important for robust ES cell propagation ${ }^{31}$.

In summary, selective inhibition of Gsk3 consolidates the ES cell ground state primarily, although not exclusively, via stabilisation of intracellular $\beta$-catenin, which eliminates the repressive influence of Tcf3 on the pluripotency network (Fig. $5 \mathrm{f,g}$ ). This mechanism is not essential when the core pluripotency factors Oct4, Sox2, Nanog, Klf2 and Klf4 are robustly expressed, but can complement activation of Stat3 and/or inhibition of Mapk to stabilise transcription of these core factors and their targets.

\section{Methods}

\section{ES cell culture}

Cells were cultured without feeders or serum, unless specifically noted, in N2B27 medium prepared as described ${ }^{2}$ or preformulated (NDiff ${ }^{\mathrm{TM}}$ N2B27 base medium, Stem Cell Sciences Ltd, Cat. No. SCS-SF-NB-02) supplemented with Small molecule inhibitors PD0325901 $(\mathrm{PD}, 1 \mu \mathrm{M})$ and CHIRON99021 $(\mathrm{CH}, 3 \mu \mathrm{M})$ and LIF prepared in house (2i+LIF). Cells were routinely propagated on $0.1 \%$ gelatine-coated plastic and replated every 3 days at a 
split ratio of 1 in 10 following dissociation with Accutase (Gibco). Alternative Gsk3 inhibitors were provided by Pfizer: Compounds A (750 nM), B (50 nM), C $(1 \mu \mathrm{M}), \mathrm{D}(250$ $\mathrm{nM}), \mathrm{E}(100 \mathrm{nM}), \mathrm{F}(150 \mathrm{nM})$ and $\mathrm{G}(50 \mathrm{nM})$ are described, see Supplementary Information, Figure 1. Colony forming assays were performed by plating $600 \mathrm{ES}$ cells per well on laminin (Sigma) coated plates. Plates were fixed and stained for alkaline phosphatase (Sigma) according to the manufacturer's protocol. Plates were scanned using a CellCelector (Aviso) and scored manually.

\author{
$\beta c a t^{f l /-}, \beta c a t^{\Delta /-}$ and Rex1GFPd2 ES cells \\ $\beta c a t^{f l /-}(\mathrm{CBC} 32)$ contain one null allele and one allele with exons 2-6 flanked by loxP \\ sites $^{40}$. $\beta c a t^{\Delta-}$ lines were established by transiently transfection using Lipofectamine2000 \\ (Invitrogen) of CAG-IRES-GFP or CAG-IRES-Cherry, sorting GFP- or Cherry-positive \\ cells by flow cytometry (see below) and seeding at low density to permit expansion of clonal \\ lines. To generate $\operatorname{Rex} 1 \mathrm{GFPd} 2$ reporter lines the entire $\operatorname{Rex} 1$ coding sequence was replaced \\ with destabilised GFP (GFPd2) linked to a blasticidin resistance cassette by homologous \\ recombination. Correct targeting was confirmed by genomic PCR.
}

\title{
Generation of $\beta$-catenin, $\beta$-catenin $\Delta C$ and Tcf3-expressing ES cell lines
}

Restriction fragments containing wild-type $\beta$-catenin and C-terminal-deleted $\beta$-catenin ( $\beta$ catenin $\Delta C)^{5}$ were cloned into pCAG-IRES-Puro. The $T c f 3(T c f 711)$ open reading frame was amplified from ES cell cDNA by PCR (Primers: AttB1-kozak- Tcf3 5' ggggacaagtttgtacaaaaaagcaggcttcaccatgccccagctcggtggtgg- $3^{\prime} ;$ Tcf3-AttB2 $5^{\prime}$ ggggaccacttgtacaagaaagctgggtcttagtgggcagacttggtga- $\left.3^{\prime}\right)$. Tcf $3 \Delta \mathrm{N}$ was in turn amplified from this by PCR (Primers: AttB1-kozak-Tcf3 $\Delta N 5^{\prime}$ -

ggggacaagtttgtacaaaaaagcaggcttcaccatggatgaggtcaagtcgtcct- $3^{\prime}$, Tcf3-AttB2 (see above)). Amplified sequences were subsequently cloned into pCAG-IRES-Puro using the Gateway system (Invitrogen). $\beta c a t^{\Delta /-}$ cells were stably transfected with full-length $\beta$-catenin or $\beta$ catenin $\Delta C$ expression vectors. Tcf3-null $\left(\mathrm{HRG} 4^{18}\right)$ ES cells were stably transfected with $\mathrm{Tcf} 3$ or $\mathrm{Tcf} 3 \Delta \mathrm{N}$ vectors. Stable transfectants were isolated by electroporation with linearised plasmid DNA and selection in $0.5-0.75 \mu \mathrm{g} / \mathrm{ml}$ puromycin.

\section{SiRNA knockdown}

siRNAs were transfected at a final concentration of 20nM using Lipofectamine RNAiMax (Invitrogen) according to the manufacturer's instructions. ES cells were transfected and maintained in $2 \mathrm{i}+\mathrm{LIF}$ overnight. Cells were then replated at low density to assess colony forming efficiency (see above) or cultured for a further 48 hours under different culture conditions before assessing Rex lGFP by flow cytometry (see below). Gsk3a, Gsk3ß and control siRNAs were obtained from Qiagen (GS606496, GS56637 and SI03650325 respectively). Tcf3 and control siRNAs were obtained from Dharmacon (TCF3 ONTARGETplus SMARTpool, L-048614-01-0005; ON-TARGET plus Non-Targeting Pool, D-001810-10).

\section{Flow cytometry}

For Pecam1 analysis cells were dissociated with cell dissociation buffer (Gibco), resuspended in PBS/1\% FCS and incubated with FITC-conjugated Pecam 1 antibody (1:200). Pecam1-FITC and GFP were analysed on a CyAn (Beckman Coulter). Cell sorting experiments were performed on a MoFlo (DAKO). For both analysis and sorting TO-PRO-3 staining was used to exclude dead cells. 


\section{Luciferase Assays}

$10^{5}$ cells per well were transfected with $0.8 \mu \mathrm{g}$ TOPFlash or FOPFlash (Upstate) and $0.04 \mu \mathrm{g}$ Renilla luciferase plasmids in 24 -well plates. $24 \mathrm{hrs}$ later cells were lysed and analysed using the dual luciferase kit (Promega) according to the manufacturer's protocol. For cotransfection experiments $1.2 \mu \mathrm{g}$ plasmid DNA was transfected together with TOPFlash.

\section{Gene expression analysis by RT-qPCR}

RNA was isolated using the RNeasy Kit (Qiagen), reverse transcribed using SuperScriptIII (Invitrogen) according to the manufacturer's instructions and analysed by real-time PCR using TaqMan Fast Universal Master Mix and TaqMan probes (Applied Biosystems) or the Universal Probe Library (UPL, Roche) system. Primers and UPL probe numbers are detailed in Supplementary Information, Table 1. Technical replicates were carried out for all qPCR reactions. An endogenous control ( $\beta$-actin or Gapdh) was used to normalise expression.

\section{Western blot analysis and immunofluorescence}

Western blots and immunofluorescence were carried out using the following antibodies at the indicated dilutions: Gsk3 (Biosource, 44-610, WB 1:1000); $\beta$-catenin (BD Biosciences, 610154, WB 1:2000, IF 1:400; Cell Signalling, 9581, IF 1:400); a-Tubulin (Abcam, ab7291, WB 1:5000); Oct3/4 (Santa Cruz, sc5279, WB 1:1000, IF 1:200); Nanog (eBiocsiences, 14-5761, WB 1:1000, IF 1:200); $\beta$ III-tubulin (Covance, MMS-435P, IF 1:500); Pecam1 (BD Biosciences, 553372, flow cytometry 1:200); active caspase 3 (R and D systems, AF835, IF 1:200)

\section{Chromatin immunoprecipitation (ChIP)}

ES cells were fixed for 10mins in $1 \%$ formaldehyde, harvested in cold PBS and incubated for 20mins on ice in swelling buffer ( $5 \mathrm{mM}$ HEPES [pH 8.25], $85 \mathrm{mM} \mathrm{KCl}$, and $0.5 \%$ NP-40). Nuclei were released with 60 strokes of a dounce homogenizer, pelleted in a microfuge and resuspended in lysis buffer (10 mM Tris [pH 8.0], $1 \mathrm{mM}$ EDTA, $0.5 \mathrm{mM}$ EGTA, and 1\% SDS). Lysates were sonicated to obtain average DNA fragment size of 500bp. Lysates were diluted 1:10 in ChIP dilution buffer (50 mM Tris-HCl [pH 8.0], 167 $\mathrm{mM} \mathrm{NaCl}, 1.1 \%$ Triton X-100, and $0.11 \% \mathrm{Na}$ Deoxycholate), pre-cleared for $2 \mathrm{~h}$ at $4 \mathrm{C}$ with protein-G sepharose beads (Amersham), and incubated overnight at $4 \mathrm{C}$ with $4 \mu \mathrm{g}$ Tcf3 antibody (Santa Cruz, sc8635). Lysates were then incubated for 30 mins at $4 \mathrm{C}$ with blocked protein-G sepharose beads, beads were washed twice each in RIPA (Tris-HCl pH 8.0, $100 \mathrm{mM}, \mathrm{NaCl}, 300 \mathrm{mM}$, EDTA pH 8.0, 2mM, Triton X-100, 2\%, SDS, $0.2 \%, \mathrm{Na}$ Deoxycholate, $0.2 \%$ ), RIPA/ $150 \mathrm{mM} \mathrm{NaCl}$ and TE. Chromatin was eluted $30 \mathrm{mins}$ at room temperature in elution buffer (Tris- $\mathrm{HCl} \mathrm{pH} 8.0,100 \mathrm{mM}, \mathrm{NaCl}, 300 \mathrm{mM}$, EDTA pH 8.0, $5 \mathrm{mM}, \mathrm{SDS}, 0.5 \%$ ). Chromatin was analysed by SYBR green real-time PCR (see primers in Supplementary Information, Table 1). Enrichment was calculated relative to control region.

\section{Supplementary Material}

Refer to Web version on PubMed Central for supplementary material.

\section{Acknowledgments}

\footnotetext{
We thank Natalia Lyashenko and Christine Hartmann for discussion and exchange of unpublished data. We also thank Alfonso Martinez-Arias for comments on the manuscript. We are grateful to Brad Merrill for generously providing Tcf3 mutant ES cells and to Brad Doble and Jim Woodgett for Gsk3 mutant ES cells. We thank Rudolf Grosschedl for the $\beta$-catenin $\Delta C$ construct. Gsk3 inhibitors, Compounds A-G, were provided by Pfizer. Rachael Walker and Peter Humphreys supported flow cytometry and imaging respectively. The study was funded by the Biotechnology and Biological Sciences Research Council and the Medical Research Council of the United
} 
Kingdom, the Wellcome Trust, and the European Commission FP7 project EuroSyStem. SGL was supported by a CONACYT Studentship. AS is a Medical Research Council Professor.

\section{References}

1. Sato N, Meijer L, Skaltsounis L, Greengard P, Brivanlou AH. Maintenance of pluripotency in human and mouse embryonic stem cells through activation of Wnt signaling by a pharmacological GSK-3-specific inhibitor. Nat Med. 2004; 10:55-63. [PubMed: 14702635]

2. Ying QL, et al. The ground state of embryonic stem cell self-renewal. Nature. 2008; 453:519-23. [PubMed: 18497825]

3. Cartwright P, et al. LIF/STAT3 controls ES cell self-renewal and pluripotency by a Myc-dependent mechanism. Development. 2005; 132:885-96. [PubMed: 15673569]

4. Doble BW, Woodgett JR. GSK-3: tricks of the trade for a multi-tasking kinase. J Cell Sci. 2003; 116:1175-86. [PubMed: 12615961]

5. Hsu SC, Galceran J, Grosschedl R. Modulation of transcriptional regulation by LEF-1 in response to Wnt-1 signaling and association with beta-catenin. Mol Cell Biol. 1998; 18:4807-18. [PubMed: 9671490]

6. Cole MF, Johnstone SE, Newman JJ, Kagey MH, Young RA. Tcf3 is an integral component of the core regulatory circuitry of embryonic stem cells. Genes Dev. 2008; 22:746-55. [PubMed: 18347094]

7. Clevers H. Wnt/beta-catenin signaling in development and disease. Cell. 2006; 127:469-80. [PubMed: 17081971]

8. Behrens J, et al. Functional interaction of beta-catenin with the transcription factor LEF-1. Nature. 1996; 382:638-42. [PubMed: 8757136]

9. Molenaar M, et al. XTcf-3 transcription factor mediates beta-catenin-induced axis formation in Xenopus embryos. Cell. 1996; 86:391-9. [PubMed: 8756721]

10. van de Wetering M, et al. Armadillo coactivates transcription driven by the product of the Drosophila segment polarity gene dTCF. Cell. 1997; 88:789-99. [PubMed: 9118222]

11. Ogawa K, Nishinakamura R, Iwamatsu Y, Shimosato D, Niwa H. Synergistic action of Wnt and LIF in maintaining pluripotency of mouse ES cells. Biochem Biophys Res Commun. 2006; 343:159-66. [PubMed: 16530170]

12. Aberle H, Bauer A, Stappert J, Kispert A, Kemler R. beta-catenin is a target for the ubiquitinproteasome pathway. EMBO J. 1997; 16:3797-804. [PubMed: 9233789]

13. Rubinfeld B, et al. Binding of GSK3beta to the APC-beta-catenin complex and regulation of complex assembly. Science. 1996; 272:1023-6. [PubMed: 8638126]

14. Hanna J, et al. Metastable pluripotent states in NOD-mouse-derived ESCs. Cell Stem Cell. 2009; 4:513-24. [PubMed: 19427283]

15. Matsuda T, et al. STAT3 activation is sufficient to maintain an undifferentiated state of mouse embryonic stem cells. EMBO J. 1999; 18:4261-4269. [PubMed: 10428964]

16. Niwa H, Burdon T, Chambers I, Smith A. Self-renewal of pluripotent embryonic stem cells is mediated via activation of STAT3. Genes Dev. 1998; 12:2048-60. [PubMed: 9649508]

17. Burdon T, Stracey C, Chambers I, Nichols J, Smith A. Suppression of SHP-2 and ERK signalling promotes self-renewal of mouse embryonic stem cells. Dev Biol. 1999; 210:30-43. [PubMed: 10364425]

18. Pereira L, Yi F, Merrill BJ. Repression of nanog gene transcription by tcf3 limits embryonic stem cell self-renewal. Mol Cell Biol. 2006; 26:7479-91. [PubMed: 16894029]

19. Guo G, Huang Y, Humphreys P, Wang X, Smith A. A PiggyBac-based recessive screening method to identify pluripotency regulators. PLoS One. 2011 Apr 18.6(4)

20. Haegel H, et al. Lack of beta-catenin affects mouse development at gastrulation. Development. 1995; 121:3529-37. [PubMed: 8582267]

21. Huelsken J, et al. Requirement for beta-catenin in anterior-posterior axis formation in mice. J Cell Biol. 2000; 148:567-78. [PubMed: 10662781] 
22. Ying QL, Nichols J, Chambers I, Smith A. BMP induction of Id proteins suppresses differentiation and sustains embryonic stem cell self-renewal in collaboration with STAT3. Cell. 2003; 115:28192. [PubMed: 14636556]

23. Bain J, et al. The selectivity of protein kinase inhibitors; a further update. Biochem J. 2007; 408:297-315. [PubMed: 17850214]

24. Doble BW, Patel S, Wood GA, Kockeritz LK, Woodgett JR. Functional redundancy of GSK-3alpha and GSK-3beta in Wnt/beta-catenin signaling shown by using an allelic series of embryonic stem cell lines. Dev Cell. 2007; 12:957-71. [PubMed: 17543867]

25. Brons IG, et al. Derivation of pluripotent epiblast stem cells from mammalian embryos. Nature. 2007; 448:191-5. [PubMed: 17597762]

26. Tesar PJ, et al. New cell lines from mouse epiblast share defining features with human embryonic stem cells. Nature. 2007; 448:196-9. [PubMed: 17597760]

27. Guo G, et al. Klf4 reverts developmentally programmed restriction of ground state pluripotency. Development. 2009; 136:1063-9. [PubMed: 19224983]

28. Soncin F, et al. Abrogation of E-cadherin Mediated Cell-cell Contact in Mouse Embryonic Stem Cells Results in Reversible LIF-independent Self-renewal. Stem Cells. 2009

29. Anton R, Kestler HA, Kuhl M. beta-Catenin signaling contributes to stemness and regulates early differentiation in murine embryonic stem cells. FEBS Lett. 2007; 581:5247-54. [PubMed: 17950287]

30. Arnold SJ, et al. Brachyury is a target gene of the Wnt/beta-catenin signaling pathway. Mech Dev. 2000; 91:249-58. [PubMed: 10704849]

31. Wray J, Kalkan T, Smith AG. The ground state of pluripotency. Biochem Soc Trans. 2010; 38:1027-32. [PubMed: 20658998]

32. Li X, et al. Generation of destabilized green fluorescent protein as a transcription reporter. J Biol Chem. 1998; 273:34970-5. [PubMed: 9857028]

33. Toyooka Y, Shimosato D, Murakami K, Takahashi K, Niwa H. Identification and characterization of subpopulations in undifferentiated ES cell culture. Development. 2008; 135:909-18. [PubMed: 18263842]

34. Robson P, Stein P, Zhou B, Schultz RM, Baldwin HS. Inner cell mass-specific expression of a cell adhesion molecule (PECAM-1/CD31) in the mouse blastocyst. Dev Biol. 2001; 234:317-29. [PubMed: 11397002]

35. Yi F, Pereira L, Merrill BJ. Tcf3 functions as a steady-state limiter of transcriptional programs of mouse embryonic stem cell self-renewal. Stem Cells. 2008; 26:1951-60. [PubMed: 18483421]

36. Tam WL, et al. T-cell factor 3 regulates embryonic stem cell pluripotency and self-renewal by the transcriptional control of multiple lineage pathways. Stem Cells. 2008; 26:2019-31. [PubMed: 18467660]

37. Kelly KF, et al. beta-catenin enhances Oct-4 activity and reinforces pluripotency through a TCFindependent mechanism. Cell Stem Cell. 8:214-27. [PubMed: 21295277]

38. Moon RT, Kimelman D. From cortical rotation to organizer gene expression: toward a molecular explanation of axis specification in Xenopus. Bioessays. 1998; 20:536-45. [PubMed: 9723002]

39. ten Berge D, et al. Wnt signaling mediates self-organization and axis formation in embryoid bodies. Cell Stem Cell. 2008; 3:508-18. [PubMed: 18983966]

40. Brault V, et al. Inactivation of the beta-catenin gene by Wnt1-Cre-mediated deletion results in dramatic brain malformation and failure of craniofacial development. Development. 2001; 128:1253-64. [PubMed: 11262227] 


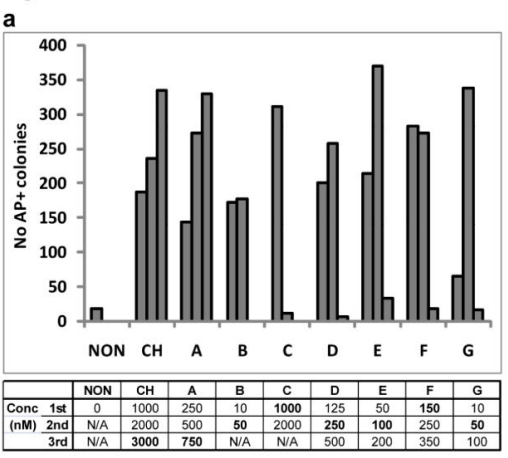

b

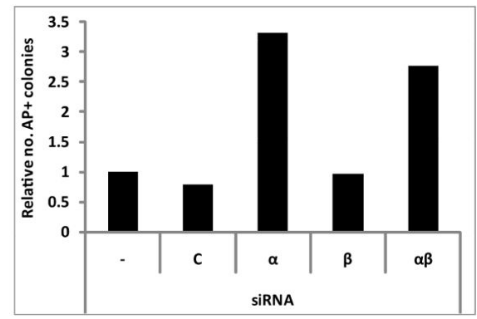

c

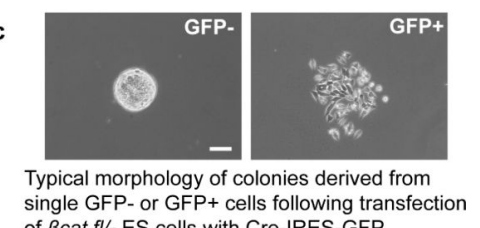

of $\beta$ cat fI/- ES cells with Cre-IRES-GFP

d
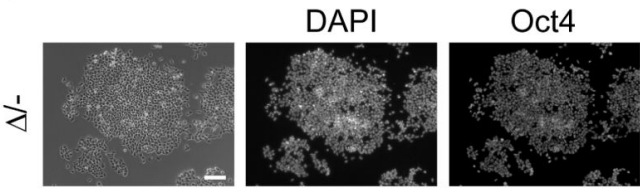

Nanog

DAPI
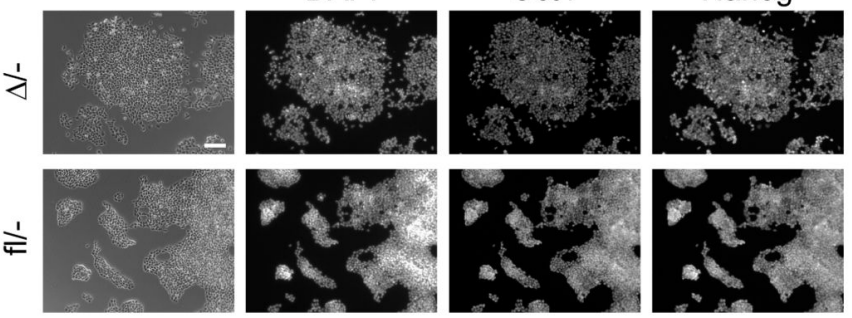

Oct4 Nanog

e

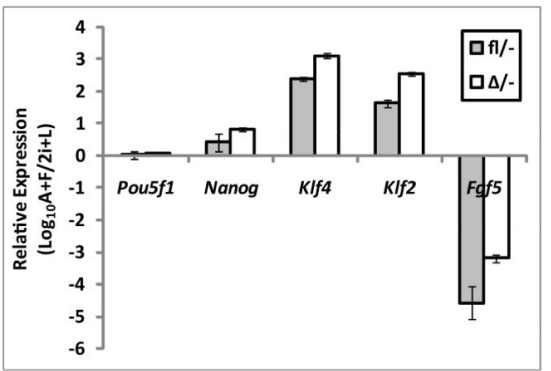

Figure 1. Suppression of Gsk3 mediates enhanced ES cell self-renewal but $\beta$-catenin is dispensable for ES cell maintenance

(a). Histogram showing number of undifferentiated (alkaline phosphatase positive, AP+), colonies formed from 600 E141VC ES cells plated in N2B27 with Mek inhibitor PD0325901 (PD, $1 \mu \mathrm{M})$ plus CHIRON99021 (CH); or alternative Gsk3 inhibitors A, B, C, $\mathrm{D}, \mathrm{E}, \mathrm{F}$, and $\mathrm{G}$ (see methods for details). Concentrations (Conc) of the inhibitors (nM) are indicated in the table beneath the graph. $1^{\text {st }}, 2^{\text {nd }}$ and $3^{\text {rd }}$ correspond to the bars from left to right. Optimum concentrations are shown in bold print.

(b). Histogram showing relative number of undifferentiated (alkaline phosphatase positive, $\mathrm{AP}+$ ), colonies formed from 600 3/4KO ES cells plated in N2B27 plus PD. Cells were untreated (-) or transfected with control siRNA (C) or siRNAs against Gsk3a (a), Gsk3 $\beta$ $(\beta)$, or both $(\alpha \beta)$. Mean of two biological replicates.

(c). Phase contrast images showing typical morphology of primary colonies isolated from GFP-negative (left) and -positive (right) fractions of $\beta$ cat $^{f^{\mathrm{ll}}-}$ ES cells transiently transfected with Cre-IRES-GFP. Note the lack of cell-cell contacts in colonies from the GFP-positive fraction. Scale bar, $200 \mu \mathrm{m}$

(d). Phase contrast and fluorescent images showing immunostaining of $\beta \mathrm{cat}^{\mathrm{fl} /-}$ and $\beta \mathrm{cat} \mathrm{t}^{\Delta /-}$ ES cells for Oct4 and Nanog. Scale bar, 100 $\mu \mathrm{m}$. 
(e). Histogram showing gene expression in $\beta c a t^{f l /-}$ and $\beta c a t^{\Delta /-}$ ES cells cultured in $2 \mathrm{i}+\mathrm{LIF}$ relative to EpiSC-like cells derived by culture in activin+FGF2 $(\mathrm{A}+\mathrm{F})$ for 7 passages. Klf4 and $K I f 2$ are specific for naive ES cells while Fgf5 is up-regulated and Nanog downregulated in $\mathrm{EpiSCs}^{27}$. Mean \pm s.d. of three biological replicates. 


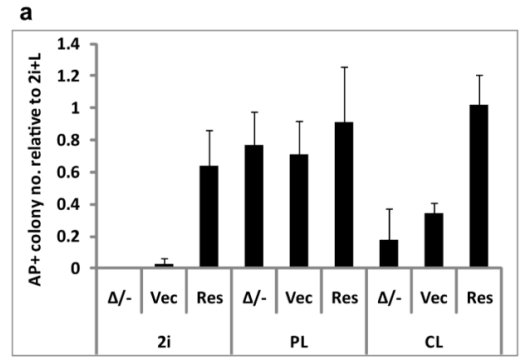

c
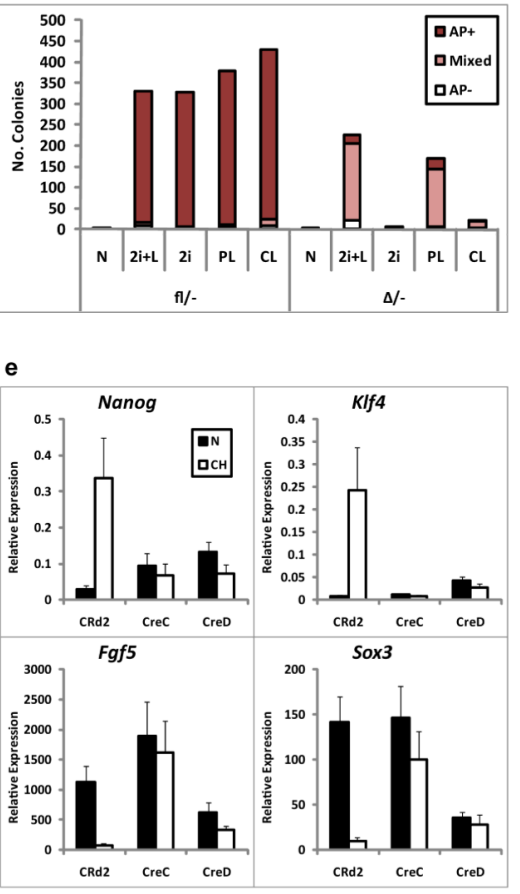

b

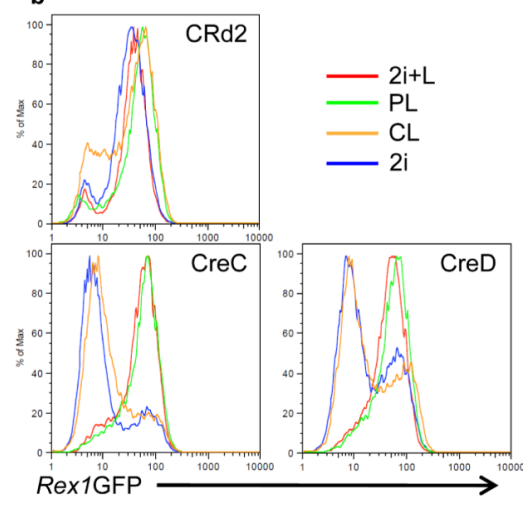

d

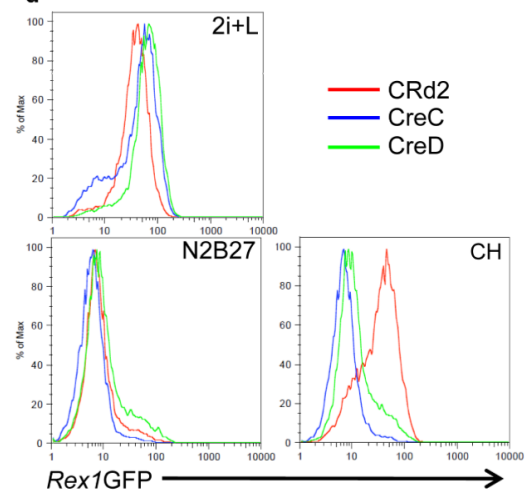

Figure 2. $\beta c a t^{\Delta-}$ ES cells do not resist differentiation upon Gsk3 inhibition (a). Histogram showing number of undifferentiated (alkaline phosphatase positive, AP+), colonies formed by parental $\beta c a t^{\Delta /-}$ or $\beta c a t^{\Delta /-}$ ES cells expressing a $\beta$-catenin transgene (Res) or the corresponding vector control (Vec) plated in N2B27 plus 2i, PD+LIF (PL) or $\mathrm{CH}+\mathrm{LIF}(\mathrm{CL})$. Data are expressed relative to the number of colonies in $2 \mathrm{i}+\mathrm{LIF}$. Mean \pm s.d. of three biological replicates.

(b). Flow cytometry analysis of Rex1GFP expression in $\beta c^{f t l} t^{f}(\mathrm{CRd} 2)$ or $\beta$ cat $^{\Delta /-}(\mathrm{CreC}$ and CreD) Rex 1 GFP reporter ES cells cultured in $2 \mathrm{i}+\mathrm{LIF}, \mathrm{PD}+\mathrm{LIF}(\mathrm{PL}), \mathrm{CH}+\mathrm{LIF}(\mathrm{CL})$ or $2 \mathrm{i}$ for 96 hours.

(c). Histogram showing number of undifferentiated (alkaline phosphatase positive, AP+), mixed and differentiated (AP-) colonies formed from $600 \beta c a t^{f l-}$ or $\beta c a t^{\Delta /-}$ ES cells plated in $2 \mathrm{i}+\mathrm{LIF}$ following 48 hours culture in N2B27 alone or plus $2 \mathrm{i}+\mathrm{LIF}(2 \mathrm{i}+\mathrm{L}), 2 \mathrm{i}$, PD+LIF (PL) or CH+LIF (CL).(d). Flow cytometry analysis of Rex $1 \mathrm{GFP}$ expression in $\beta$ cat ${ }^{f l}-$ $(\mathrm{CRd} 2)$ or $\beta c a t^{\Delta /-}(\mathrm{CreC}$ and CreD) Rex $1 \mathrm{GFP}$ reporter ES cells cultured in 2i+LIF, N2B27 alone or $\mathrm{CH}$ for 48 hours.

(e). Histogram showing relative expression of pluripotency markers Nanog and Klf4 and early differentiation markers Fgf5 and Sox 3 in $\beta c a t^{f l-}(\mathrm{CRd} 2)$ or $\beta c a t^{\Delta /-}(\mathrm{CreC}$ and CreD) Rex 1GFP reporter ES cells cultured in $2 \mathrm{i}+\mathrm{LIF}$, or N2B27 alone or plus $\mathrm{CH}$ for 48 hours. Mean \pm s.d. of three biological replicates. 


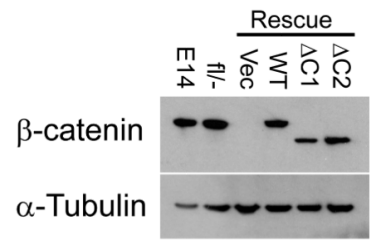

c

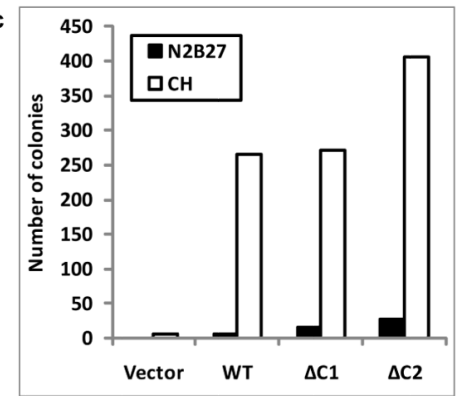

e

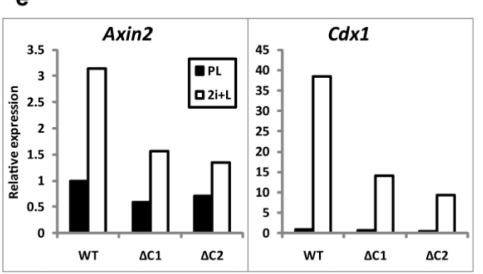

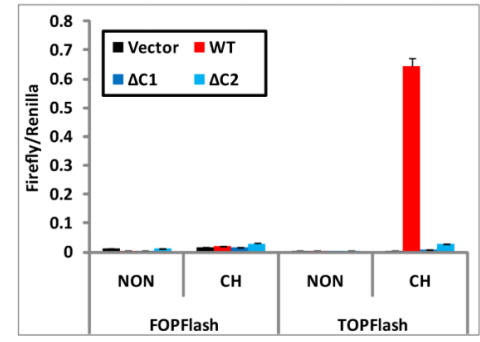

d

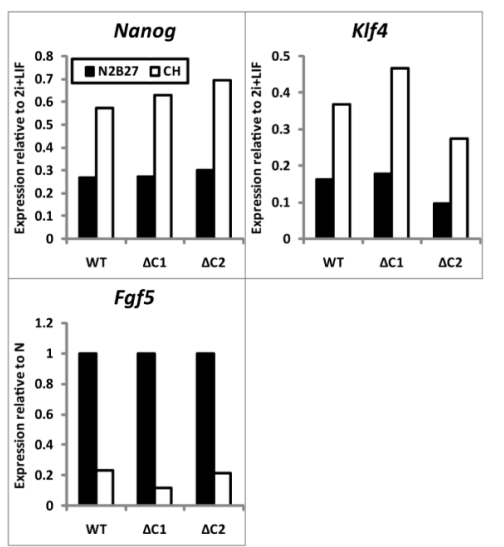

Figure 3. $\beta$-catenin inhibits differentiation independent of its transcriptional activation domain (a). Western blot showing $\beta$-catenin and $\alpha$-Tubulin (loading control) expression in wild-type (E14), $\beta c a t^{f l /-}$ or "Rescue" $\beta c a t^{\Delta /-}$ ES cells expressing randomly integrated wild-type (WT) or C-terminal-deleted $\beta$-catenin $(\Delta \mathrm{C})$ transgenes or the corresponding vector control (Vec). $\Delta \mathrm{C} 1$ and $\Delta \mathrm{C} 2$ are independent clones. Uncropped images of blots are shown in Supplementary Fig. S9.

(b). Histogram showing TOPFlash and FOPFlash reporter activity in $\beta$ cat ${ }^{\Delta /-}$ cells expressing randomly integrated wild-type (WT) or C-terminal-deleted $(\Delta \mathrm{C}) \beta$-catenin transgenes in PD+LIF with or without $\mathrm{CH} . \Delta \mathrm{C} 1$ and $\Delta \mathrm{C} 2$ are independent clones. Mean \pm s.d. of three biological replicates.

(c). Histogram showing number of undifferentiated colonies formed from $600 \beta c a t^{\Delta /-}$ cells expressing randomly integrated wild-type (WT) or C-terminal-deleted $(\Delta \mathrm{C}) \beta$-catenin transgenes plated in $2 \mathrm{i}+\mathrm{LIF}$ after 48 hours in N2B27 alone or plus $\mathrm{CH}$.

(d) Histograms showing relative expression of Nanog, Klf4, and Fgf5 in $\beta c a t^{\Delta /-}$ cells expressing randomly integrated wild-type (WT) or C-terminal-deleted $\beta$-catenin $(\Delta \mathrm{C})$ transgenes cultured in $2 \mathrm{i}+\mathrm{LIF}$ or in $\mathrm{N} 2 \mathrm{~B} 27$ alone or plus $\mathrm{CH}$ for 24 hours. Expression is shown relative to levels in $2 \mathrm{i}+\mathrm{LIF} . \Delta \mathrm{C} 1$ and $\Delta \mathrm{C} 2$ are independent clones.

(e). Histogram showing relative expression of $A x i n 2$ and $C d x 1$ in $\beta c a t^{\Delta /-}$ cells expressing randomly integrated wild-type (WT) or C-terminal-deleted $(\Delta \mathrm{C}) \beta$-catenin transgenes cultured in PD+LIF or 2i+LIF for 48 hours.

Data in (c)-(e) are mean of two biological replicates. 

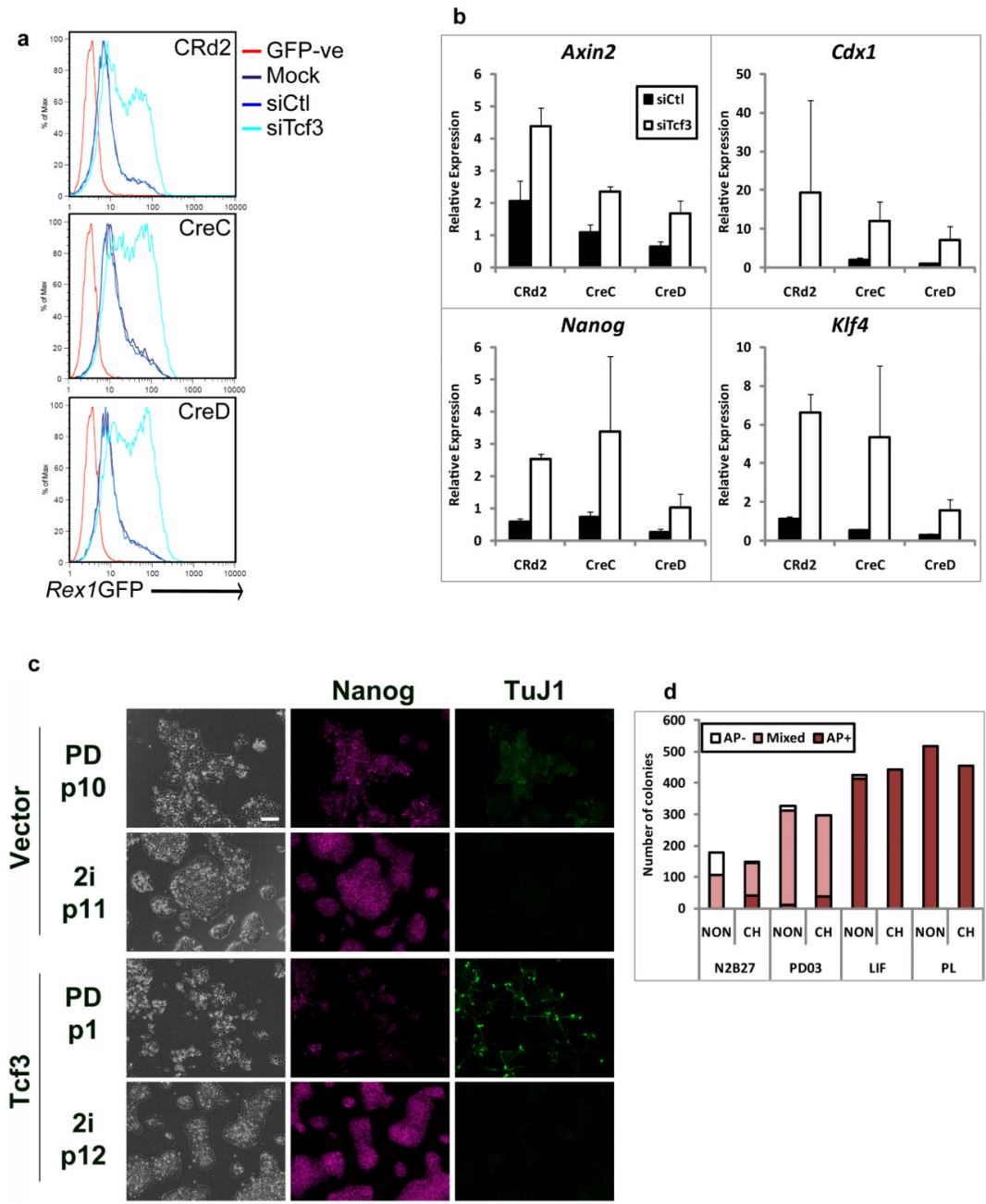

Figure 4. $\beta$-catenin functions by abrogating Tcf3 repression

(a). Flow cytometry analysis showing the profile of $\operatorname{Rex} 1 \mathrm{GFP}$ expression in $\beta$ cat ${ }^{f l-}(\mathrm{CRd} 2)$ or $\beta c a t^{\Delta /-}$ (CreC and CreD) Rex 1GFP reporter ES cells mock transfected (Mock) or transfected with control siRNAs (siCtl) or siRNA against $T c f 3$ (siTcf3) and cultured for 48 hours in N2B27 alone. GFP-ve: wild-type ES cells that do not express GFP. (b). Histograms showing relative expression of Axin2, Cdx 1 , Nanog and Klf4 in $\beta c a t^{f l-}$ (CRd2) or $\beta c a t^{\Delta /-}$ (CreC and CreD) Rex 1 GFP reporter ES cells. Cells were cultured for 24 hours in N2B27 alone and were transfected with control siRNAs (siCtl) or siRNAs against $T c f 3$ (siTcf3). Expression is shown relative to untreated. Mean \pm s.d. of three biological replicates.

(c). Phase contrast and fluorescent images showing Nanog and BIII-tubulin (TuJ1) expression in $T c f 3$-null ES cells stably expressing a randomly integrated $T c f 3$ transgene or the corresponding vector control cultured in N2B27 plus PD or plus 2i for the indicated number of passages (p). Scale bar, $100 \mu \mathrm{m}$.

(d). Histogram showing number of undifferentiated (AP+), mixed and differentiated (AP-) colonies formed from 600 Tcf3-null ES cells in N2B27 alone or plus PD, LIF or PD+LIF in the presence or absence of $\mathrm{CH}$ 

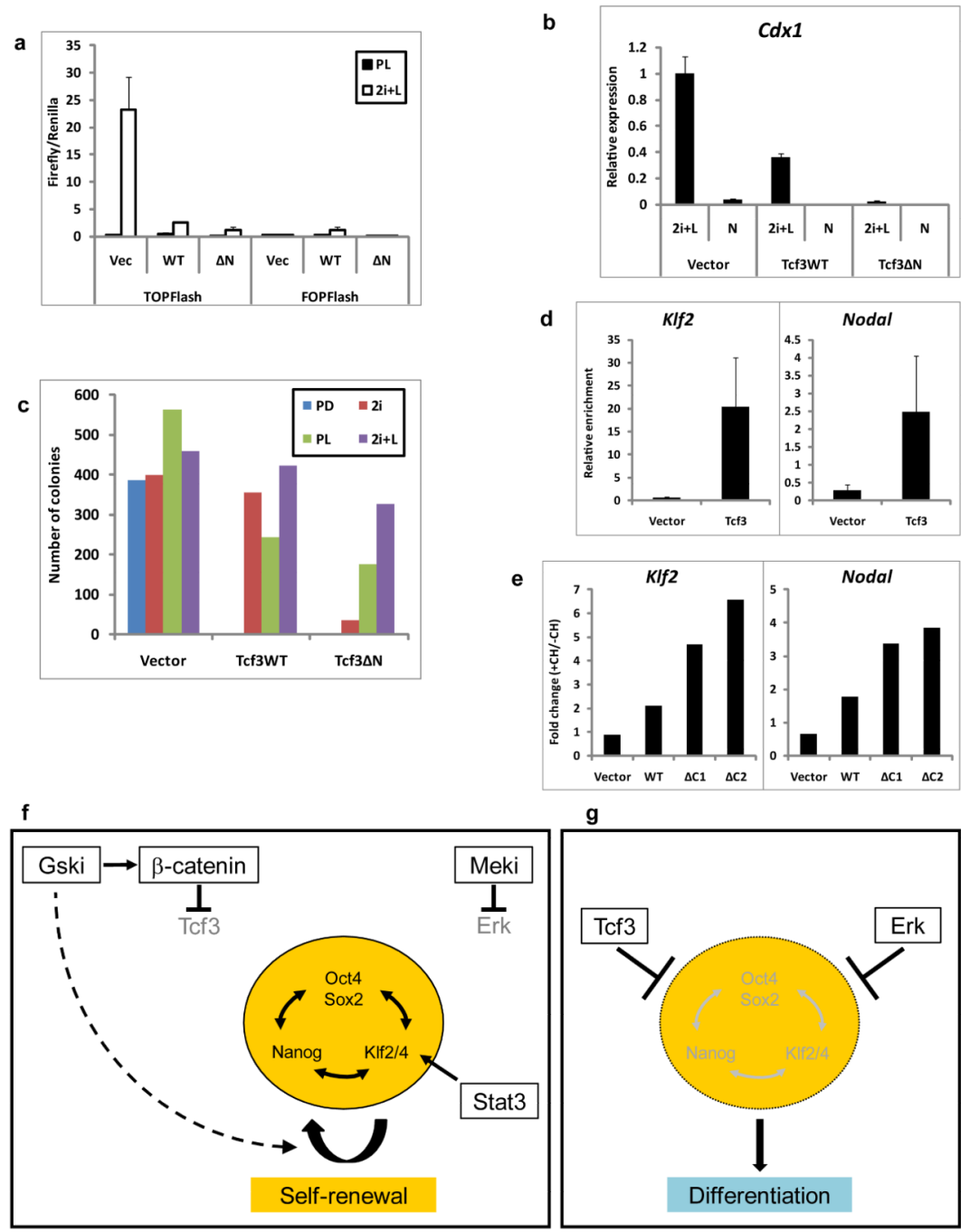

d

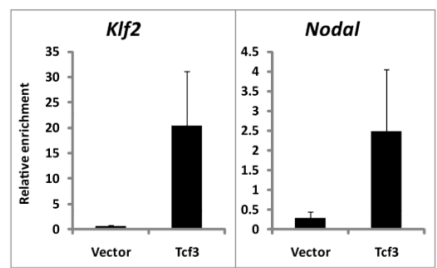

e
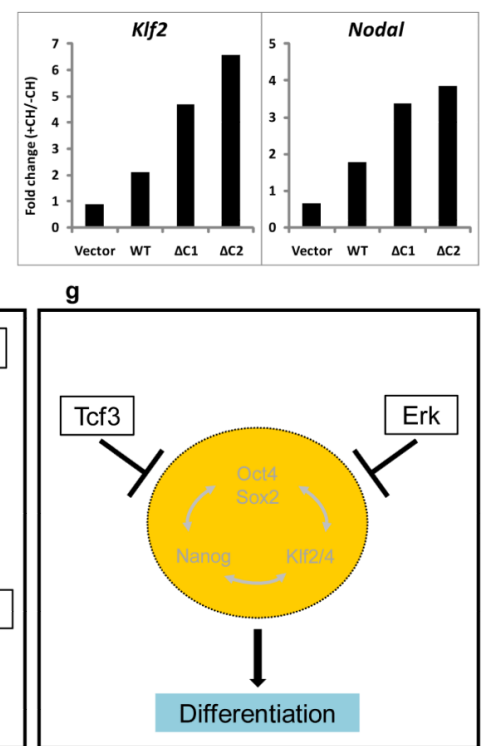

Figure 5. Gsk3 Inhibition Relieves the Core Pluripotency Network from Repression by Tcf3 and Complements Mek Inhibition and/or Stat3 Activation to Stabilise ES Cell Self-Renewal

a) Histogram showing TOPFlash and FOPFlash activation in Tcf3-null ES cells stably expressing randomly integrated wild-type (WT) or N-terminal-deleted $(\Delta \mathrm{N}) T c f 3$ transgenes or the corresponding vector control (Vec) in PD+LIF(PL) or $2 \mathrm{i}+\mathrm{LIF}(2 \mathrm{i}+\mathrm{L})$. Mean \pm s.d. of three biological replicates is shown

b) Histogram showing relative expression of $\mathrm{Cdx} 1$ in $T c f 3$-null ES cells stably expressing randomly integrated wild-type (Tcf3WT) or N-terminal-deleted (Tcf3 $\Delta \mathrm{N})$ Tcf3 transgenes or the corresponding vector control in $2 \mathrm{i}+\mathrm{LIF}(2 \mathrm{i}+\mathrm{L})$ or N2B27 alone. Mean \pm s.d. of three biological replicates is shown

c) Histogram showing number of undifferentiated colonies formed from 600 Tcf3-null ES cells stably expressing randomly integrated wild-type (Tcf3WT) or N-terminal-deleted (Tcf3 $\Delta \mathrm{N})$ Tcf3 transgenes or the corresponding vector control in N2B27 plus PD, 2i, PD $+\mathrm{LIF}(\mathrm{PL})$ or $2 \mathrm{i}+\mathrm{LIF}(2 \mathrm{i}+\mathrm{L})$. Mean of two biological replicates.

d) Histogram showing relative enrichment of Klf2 and Nodal promoter regions following chromatin immunoprecipitation for Tcf3 in Tcf3-null ES cells stably expressing a randomly integrated $T c f 3$ transgene or the corresponding vector control. Mean \pm sd of three replicates is shown 
e) Histogram showing response to $\mathrm{CH}$ of $\mathrm{Klf2}$ and Nodal in $\beta c a t^{\Delta /-}$ cells expressing randomly integrated wild-type (WT) or C-terminal-deleted $(\Delta \mathrm{C}) \beta$-catenin transgenes cultured in N2B27 alone for 24 hours followed by 8 hours in N2B27 plus PD in the presence or absence of $\mathrm{CH}$. Mean ratio $(+\mathrm{CH} /-\mathrm{CH})$ of two biological replicates.

f) In the presence of Gsk-3 inhibitor (Gski) and a mitogen activated protein kinase (Erk) kinase inhibitor (Meki), repressive effects on the pluripotent gene regulatory network are abolished. The pluripotent circuitry is also positively regulated by Stat 3 acting primarily through Klf4. Any two of these three effects are sufficient to stabilise the network and sustain ES cell self-renewal. Gski generates intracellular $\beta$-catenin which interacts with Tcf3 and abolishes its repressor effect on multiple genes in the pluripotent network. Gski additionally supports ES cell propagation through stimulatory effects on metabolic and biosynthetic processes (dashed arrow).

g) In the absence of inhibitors, Tcf3 repression and activated Erk drive ES cells into differentiation.

When ES cells are maintained in serum using LIF without inhibitors, cultures are heterogeneous and metastable due to co-existence of states (f) and (g). 
$\frac{-}{\frac{0}{0}}$

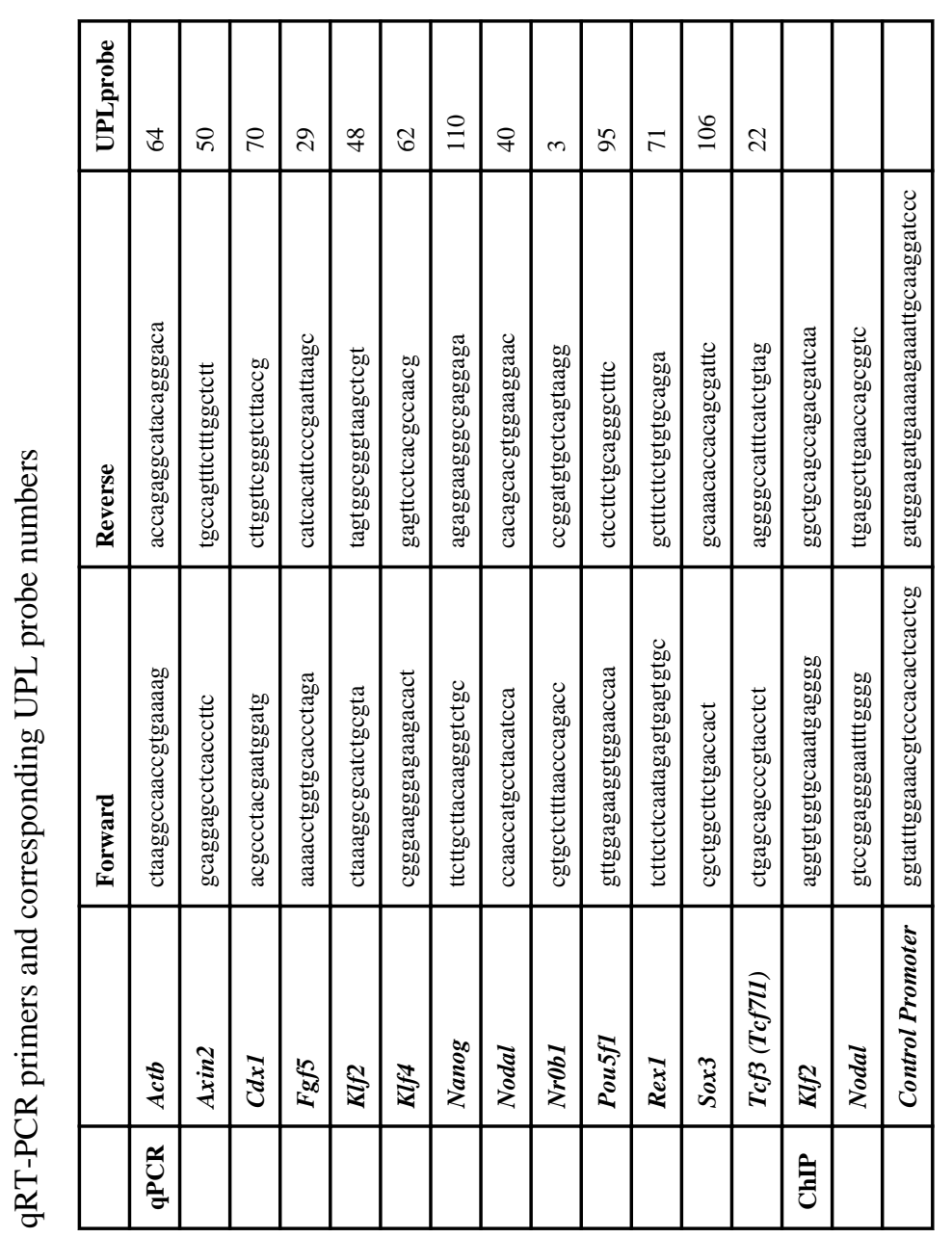

